\title{
Warum dieser Leitfaden?
}

„Was soll ich mit einem Leitfaden für Moderation, Präsentation und freier Rede?“ Veranstaltungen organisiere ich nicht - und moderieren werde ich so etwas auch nie. „Ein Glück, dass ich das nicht muss.“ mag eine häufige Auffassung sein.

Hier wird aber völlig übersehen, was eine Moderation auch im Berufsalltag oder bei Freizeitbetätigungen sein kann. Denn jede Besprechung, jeder Jour fixe, alle regelmäßigen Projektkonsultationen mit internen Kollegen oder externen Kunden oder Lieferanten müssen geleitet - und damit moderiert - werden.

Haben sie schon einmal an einer Besprechung teilgenommen, bei der sich niemand für die Leitung des Gespräches verantwortlich gefühlt hat?

Wie ist das Gespräch verlaufen? Welche Ergebnisse wurden erzielt?

Ach - Sie können sich gar nicht mehr erinnern? Besten Dank für die Bestätigung. Jetzt wissen Sie es bereits: Moderation auch in diesen Fällen eine

- wichtige,

- nicht zu vernachlässigende und vor allem

- nicht zu unterschätzende, weil

- anspruchsvolle Aufgabe.

Als Projekt- oder Teilprojektleiter ist diese Aufgabe der Moderation natürlich nur eine unter vielen. Deren gute und gewissenhafte Erledigung vereinfacht aber die projekt- oder teaminterne Kommunikation um ein Vielfaches. Daher ist es lohnenswert, sich mit diesen Dingen zu befassen - es zahlt sich meines Erachtens immer aus. 